\title{
Transperineal cryotherapy for unresectable muscle invasive bladder cancer: preliminary experience with 7 male patients
}

\author{
Qing Zhang ${ }^{\dagger}$, Shiwei Zhang ${ }^{\dagger}$, Shun Zhang, Wei Wang, Xiaozhi Zhao, Yongming Deng, Huibo Lian \\ and Hongqian Guo*
}

\begin{abstract}
Background: Radical cystectomy (RC) with pelvic lymph node dissection (PLND) and urinary diversion (UD) is considered the standard treatment for muscle invasive bladder cancer (MIBC). In a part of patients, RC procedure is aborted due to unresectable disease, other followed treatment like systemic chemotherapy, radiotherapy or cryotherapy may be a better option. The aim of present study was to report the preliminary results of transperineal cryotherapy for unresectable muscle invasive bladder cancer.

Methods: From January 2011 to August 2013, 7 male patients with pT4b unresectable bladder cancer underwent bilateral ureterocutaneostomy. Two performed a pelvic lymph node dissection (PLND). Then primary transperineal cryosurgery for preserved bladder at the guidance of transrectal ultrasound (TRUS) was performed. All patients underwent a dual freeze-thaw cycle using third-generation cryotechnology with ultrathin 17-gauge cryoneedles. Computer tomography (CT) and/or magnetic resonance image (MRI)were performed at 3 month intervals after cryosurgery to determine whether progression or recurrence occurred.

Results: All cryosurgery was performed successfully, mean operation time was $76.43 \pm 25.12$ min (range 50-120 min), mean blood loss was $19.29 \pm 15.92 \mathrm{ml}$ (range 5-50 ml). Mean hospital stay was $3.86 \pm 1.68$ day (range 27 days). No operative related deaths occurred. Four patients dead due to the metastasis disease at the follow up time of 8, 15, 18 and 37 months, respectively. Six patients received postoperative therapy, of whom 5 patients were treated with combined chemoradiation, and the other one received chemotherapy alone. The progression free survival (PFS) of the 7 patients was $22.00 \pm 14.61$ months (range 3-40 months). The one, two and three year overall survival (OS) was 85.7\%, 57. $1 \%$ and $42.9 \%$, respectively.
\end{abstract}

Conclusion: Our results suggest that cryosurgery combination with chemoradiotherapy provide a safe and effective alternative method for unresectable pT4b bladder cancer. Longer follow-up is necessary to determine the sustained efficacy.

Keywords: Cryotherapy, Invasive bladder cancer, Progression free survival, Transperineal cryoablation, Unresectable

\section{Background}

Bladder cancer $(\mathrm{BC})$ is a common human malignancy and is the second most common genitourinary malignancy [1]. About $20-40 \%$ of patients with $\mathrm{BC}$ present or develop a muscle invasive bladder cancer (MIBC). Currently, radical cystectomy (RC) with pelvic lymph node dissection (PLND)

\footnotetext{
* Correspondence: dr.ghq@nju.edu.cn

${ }^{\dagger}$ Equal contributors

Department of Urology, Drum Tower Hospital, Medical School of Nanjing University, Institute of Urology, Nanjing University, 321 Zhongshan Road, Nanjing 210008, Jiangsu, People's Republic of China
}

and urinary diversion (UD), although associated with significant morbidity, is considered the standard treatment for MIBC [2]. In a part of patients, RC procedure is aborted due to unresectable disease, either the presence of gross palpable nodes (pN2-3) or tumor fixation to the pelvis or rectum (pT4b). In these patients, $R C$ will be aborted intraoperatively, other followed treatment like systemic chemotherapy, radiotherapy or cryotherapy may be a better option.

Cryosurgery, which can induce tissue necrosis by ice ball formation, has been used as an alternative therapeutic 
approach in bladder cancer for half a century. The effects of cryoablation on the bladder were investigated in dogs by McDonald et al. in 1950 and typical necrotic lesions were produced [3]. Several reports recently described the utility of cryosurgery in the treatment of bladder cancer through percutaneous or transurethral route and concluded that this precudure could be used as a novel therapeutic approach to the treatment of benign and malignant bladder tumors, especially unresectable tumors and metastatic bladder cancer $[4,5]$.

Since 2011, we have performed transperineal cryotherapy in patients who had aborted RC with unresectable disease secondary to fixation to the pelvis and/or rectum and followed ureterocutaneostomy. The aim of the current study was to analyze the preliminary results and to investigate the safety and efficacy of transperineal cryotherapy in our 7 male patients.

\section{Methods \\ Patients}

Between January 2011 to August 2013, 7 male patients with unresectable bladder cancer underwent transperineal cryotherapy in our institution were enrolled in the study. All patients had an aborted RC due to unresectable disease secondary to fixation to the pelvis and/or rectum (pT4b) then the followed ureterocutaneostomy was performed. Preoperative work-ups were performed, including serum blood tests, chest X-ray, abdomen/pelvis computed tomography scans (CT) (Fig. 1a and b), and bone scans if clinically indicated. Moreover, each patient underwent a staging cystoscopy with transurethral resection of bladder tumor (TURBT). Preoperative CT and/or MRI scans were negative for pelvic adenopathy, metastasis, or evidence of clinically unresectable disease (Fig. 1a and b). The pre-anesthetic risk was quantified using the American Society of Anesthesiologist's physical status classification score. No neoadjuvant chemotherapy was applied. Then cryoablation was performed on the preserved bladder at the second time and the followed adjuvant chemoradiotherapy or chemotherapy alone was performed (Gemcitabine and cisplatin regimens chemotherapy were added to patients 3 months later after cryoablation, followed local radiotherapy for bladder cancer). Each patient provided written informed consent, and the study was approved by Ethics Committee of Nanjing Drum Tower Hospital. Patient demographics were summarized in Table 1.

\section{Ureterocutaneostomy and PLND}

RC with appropriate LND and UD was the preferred treatment for patients with MIBC. However, RC could not be achieved due to the diseases of the fixation to the pelvis and/or rectum (pT4b) or the presence of gross palpable nodes (pN2-3) according intraoperative findings. All the patients were pT4b stage and urinary diversion was performed with bilateral ureterocutaneostomy. Two of the 7 patients had a PLND, and 5 did not at the discretion of the treating surgeon in our study. Ureterocutaneous anastomosis was performed according to the technique originally described by Glenn [6].

\section{Cryosurgery procedure}

All cryosurgery procedures were performed using the Cryo-Hit System (Galil Medical Ltd., Israel) by a single urologist. All patients were placed in a modified lithotomy position under spinal anesthesia. The scrotum was elevated off the perineum after a 18F Foley catheter was inserted into bladder. The template was placed in stepper, approximate to perineum, and the grid was overlaid on ultrasound screen (Fig. 2a). The template and ultrasound grid were verified alignment with first needle. All needles were tested before insertion. Under transrectal ultrasound (TRUS) guidance, 1.47-mm 17G IceSeed cryoneedles were placed transperineally into the bladder tumor (Fig. 2b and c). Two single-point temperature monitoring probes were placed at tumor around and rectum, respectively. The number and position of cryoneedles varied with bladder cancer size and location. Freezing with argon gas to $<-40{ }^{\circ} \mathrm{C}$ was initiated and monitored using the temperature-monitoring probes, and TRUS guidance, which revealed an acoustic shadow as the ice-ball formed (Fig. 2d). The tumor around and rectum was maintained at temperatures greater than $0^{\circ}$ $\mathrm{C}$, and freezing was stopped when the iceball reached the anterior rectal wall was at least $20{ }^{\circ} \mathrm{C}$. After maintaining $-40{ }^{\circ} \mathrm{C}$ or the lowest temperature below $-25^{\circ}$ Cfor $10 \mathrm{~min}$, a passive thaw was initiated until the temperature reached a plateau. At this point, active thawing with helium was started. Two cycles of rapid freeze-thaw were carried out, ensuring the temperature in the bladder cancer and just outside it was below a therapeutic value of $-40{ }^{\circ} \mathrm{C}$. At the end of the procedure, the needles and probes were removed and pressure applied to the perineal area for $10 \mathrm{~min}$ to reduce bruising.

\section{Follow up evaluation and statistical analysis}

Radiographic local tumor control was assessed using image-guided tumor ablation criteria [7]. Follow-up CT and MRI were performed at 3-month intervals after cryotherapy procedure. Two diagnostic radiologists reviewed CT and MRI scans for every case to determine whether progression or recurrence had occurred. Progression free survival (PFS) and overall survival (OS) were calculated from the date of cryosurgery. Data are presented as the mean \pm standard deviation (SD). Analyses were performed with Statistical Package for Social Sciences, version 17 (SPSS, Chicago, IL). 

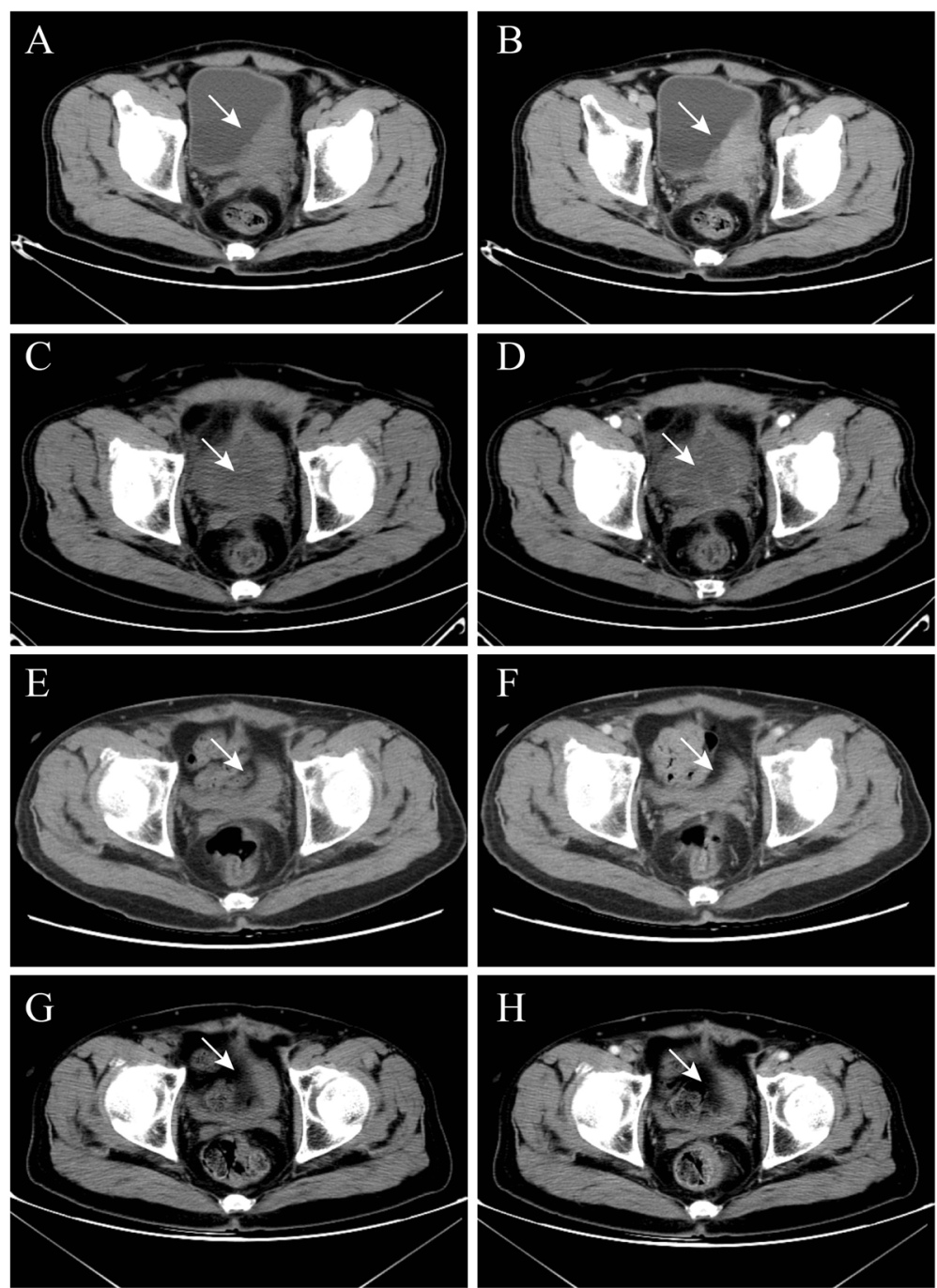

Fig. 1 CT images of a patient with cancer in the left wall of the bladder (patient number 5)Non-contrast (a) and contrast-enhanced arterial phase images (b) of CT scans indicated that the tumor (white arrow) located on left wall of bladder, the longest diameter of tumor was $8.1 \mathrm{~cm}$ before cryosurgery. One months after cryosurgery, non-contrast (c) and contrast-enhanced arterial phase images (d) of CT show the structure of the bladder wall remained intact and tumor (white arrow) inside and outside the bladder had no obviously enchancement. One year after cryosurgery, noncontrast (e) and contrast-enhanced arterial phase $\subset T$ images (f) show the bladder (white arrow) contraction and no urinary filling. There was no obviously enchancement in the preserved bladder. Three year after cryosurgery, non-contrast (g) and contrast-enhanced arterial phase images $(\mathbf{h})$ of $\subset$ show the bladder (white arrow) shrink further and no obviously enchancement in the shrinked bladder. No progression and local recurrence happened in this patient at the follow up time of 40 months

\section{Results}

Totally 7 male patients were included in this study. The clinical characteristics of the 7 patients are summarized in Table 1. The mean age of patients was $60.14 \pm 9.04$ years (range from 47 to 73 years) with a mean follow-up of patients alive of $28.43 \pm 14.25$ months (range from 8 to 43 months). Five patients were found to have hydronephrosis, either unilateral or bilateral. Histology showed all these patients were high grade urothelial carcinoma according to TURBT and the followed biopsy. Tumors were located in the right, left or back wall of the bladder in two, four, and one cases, respectively. The mean tumor longest diameter was $7.87 \pm 1.79 \mathrm{~cm}$ (range from 5.8 to $11.4 \mathrm{~cm}$ ). All 7 patients planned to cystectomy, but underwent aborted cystectomy due to unresectable disease secondary to fixation to the pelvis and/or rectum (pT4b stage) according to the intraoperative findings and the followed ureterocutaneostomy was performed. Mean time from ureterocutaneostomy to cryosurgery was $6.00 \pm 1.63$ months (ranging from 4 to 9 months). Two of the 7 patients had a PLND, and the other 5 had no PLND at the discretion of the treating surgeon. No positive pelvic lymph nodes were found in followed histopathological examination of the two patients. 
Table 1 Data for 7 male patients (age range from 47 to 73 years) who underwent transperineal cryotherapy for high grade MIBC

\begin{tabular}{|c|c|c|c|c|c|c|c|}
\hline Patients & $\mathrm{TLD}(\mathrm{cm})$ & $O P(\min )$ & PFS(month) & Location & Initial symptom & $\begin{array}{l}\text { Complications } \\
\text { Post-cryosurgery }\end{array}$ & Additional Treatment \\
\hline 1 & 7.5 & 55 & 11 & Left wall & Hematuria & None & Chemoradiotherapy \\
\hline 2 & 8.3 & 70 & 25 & Left wall & Urinary irritation & Urinary irritation & Chemoradiotherapy \\
\hline 3 & 6.5 & 50 & 35 & Left wall & $\begin{array}{l}\text { Hematuria, Urinary } \\
\text { irritation, Abdominal } \\
\text { pain }\end{array}$ & $\begin{array}{l}\text { Abdominal } \\
\text { pain }\end{array}$ & Chemotherapy \\
\hline 4 & 11.4 & 120 & 3 & Right wall & Hematuria & None & None \\
\hline 5 & 8.1 & 100 & 40 & Left wall & Hematuria, Abdominal pain & None & Chemoradiotherapy \\
\hline 6 & 5.8 & 75 & 8 & Back wall & Hematuria & None & Chemoradiotherapy \\
\hline 7 & 7.5 & 65 & 32 & Right wall & $\begin{array}{l}\text { Hematuria, Urinary } \\
\text { irritation }\end{array}$ & None & Chemoradiotherapy \\
\hline
\end{tabular}
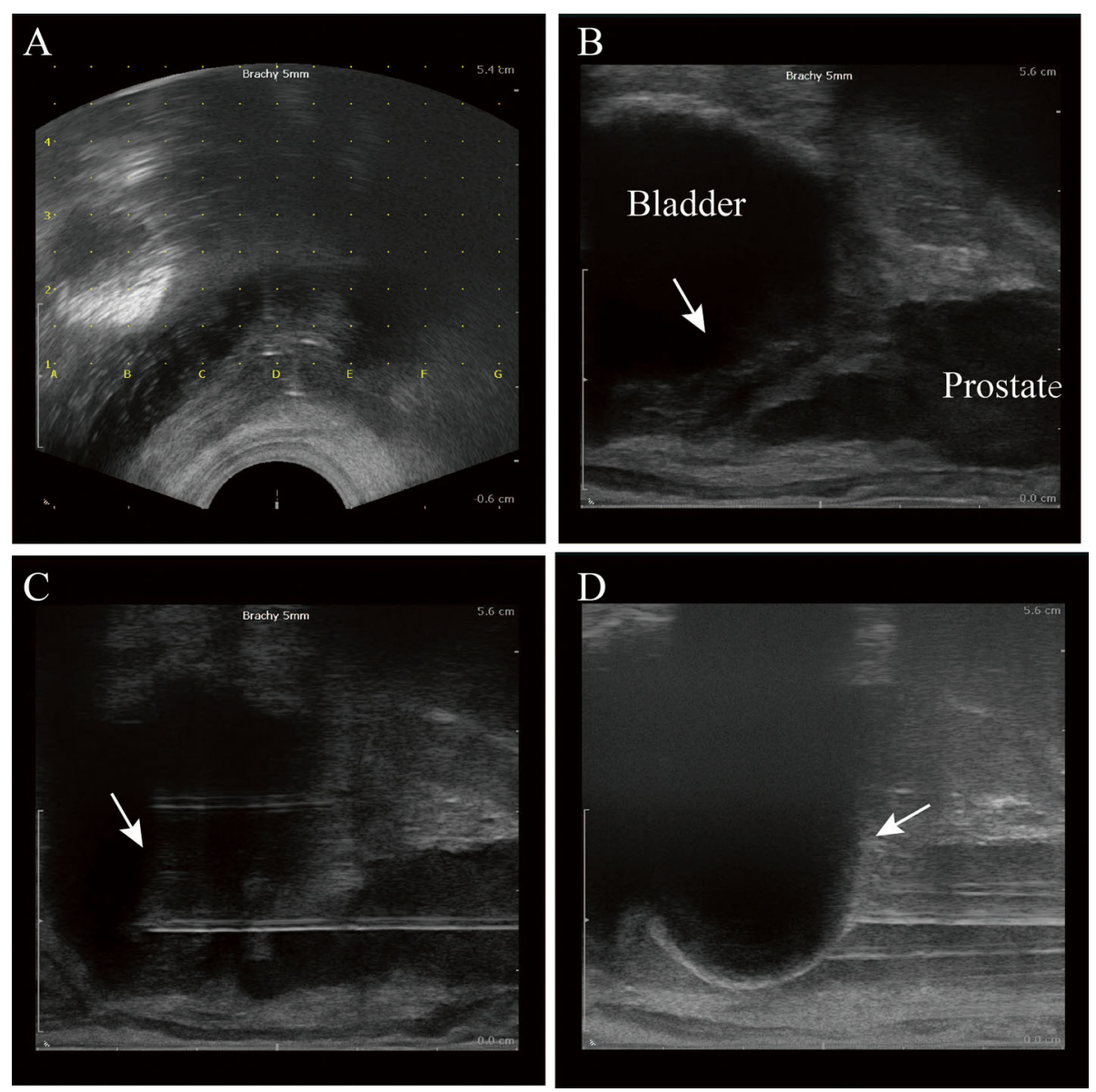

Fig. 2 Images of transperineal cryotherapy procedure for unresectable muscle invasive bladder cancer under the real-time guidance of TRUS (patient number 5). The template was placed in stepper, approximate to perineum, and the grid was overlaid on ultrasound screen (a). Bladder tumor (white arrow) and other nearby tissues and organs including prostate and rectum were identified by TRUS (b). Under TRUS guidance, two 1.47-mm 17G IceSeed cryoneedles were placed transperineally into the bladder tumor (white arrow) (c). Two single-point temperature monitoring probes were placed at tumor around and rectum, respectively. Freezing with argon gas to $<-40{ }^{\circ} \mathrm{C}$ was initiated and monitored using the temperature-monitoring probes, and TRUS guidance, which revealed an acoustic shadow as the ice-ball formed (white arrow) (d) 
All the cryosurgery procedures were performed successfully and all patients well tolerated with the transperineal cryosurgery, and with minimal requirements for pain medication and without the need for blood transfusions. No operative-related deaths occurred in these patients. The mean operative time of transperineal cryosurgery was $76.43 \pm 25.12 \mathrm{~min}$ (range from 50 to $120 \mathrm{~min}$ ). The mean bleed loss was $19.29 \pm 15.92 \mathrm{ml}$ (range from 5 to $50 \mathrm{ml}$ ). The mean length of hospital stay for the patients after cryosurgery was $3.86 \pm 1.68$ days (range from 2 to 7 days). In the process of follow-up, all patients have abandoned freezing treatment again, and two patients' dead due to pulmonary metastasis disease at the follow up time of 8 and 37 months, the other two patients' dead due to extensive abdominal and pelvic metastasis at 15 and 18 months after cryosurgery respectively. The other three patients were alive at 43,40 and 38 months after cryosurgery and no progression of disease at the follow up examination of CT (Fig. $1 \mathrm{c}-\mathrm{h})$. There were minor complications but no major complications of the treatment. These new treatment-related symptoms are not considered as complications and no other minor or severe complications were noticed. All complications had disappeared completely after 2 weeks. Six of 7 patients received postoperative therapy, of whom 5 patients were treated with combined identical chemoradiation, while the other one received chemotherapy alone. The PFS of the 7 patients was $22.00 \pm 14.61$ months (range 340 months). The one, two and three-year OS was $85.7 \%$, $57.1 \%$ and $42.9 \%$, respectively.

\section{Discussion}

$\mathrm{BC}$ is currently one of the tumors with the most rapid increase in incidence. At the time of diagnosis, approximately $15 \%$ of patients who present with bladder cancer will be found to have regional or distant metastasis [8-10]. Radical cystectomy with PLND and UD continues to be the gold standard for MIBC [11]. It is a clinical and therapeutic dilemma when these tumors are found to be unresectable (pN2-3 or pT4b) on surgical exploration. In this situation, chemotherapy and/or radiotherapy are the only treatment that has been shown to improve survival as described previously $[12,13]$. However, systemic chemotherapy and radiotherapy may have severe side effects, such as significant hematologic, mucosal toxicity or gastrointestinal bleeding or perforation [14], or lead to treatment-related death [15].

Faysal A. Yafi et al. addressed the outcomes of thirtyone patients who underwent aborted RC due to unresectable disease. The outcome of patients with unresectable disease is dismal. The 2 - and 5 -year OS was $41 \%$ and $0 \%$, respectively. They get the conclusion that patients who had an aborted cystectomy due to unresectable disease may benefit from PLND and upfront chemotherapy [11]. Recently, a study included 35 patients who had an aborted radical cystectomy for intraoperative findings of metastatic bladder cancer [16]. It showed a poor prognosis for these patients with a median time to cancer-specific survival of 26.5 months, and OS at one, two, and three years of $67 \%$, $43 \%$, and $18 \%$ respectively. Other several literatures reported that adjuvant radiotherapy also has the ability to improve the OS and PFS in patients with MIBC $[14,17]$. From these results of previous studies, the survival enhancement was not very satisfying in combined chemoradiation or chemotherapy/radiotherapy alone.

Cryosurgery, also known as cryoablation, is widely used as primary or salvage treatment for various urological malignances like renal cell carcinoma (RCC) and prostate cancer (PC) in recent years [18-21]. It is reported that cryosurgery offers benefits with fewer complications, shorter hospitalization times, and allows for quicker convalescence in the treatment of RCC and PC [22-25]. Transperineal cryosurgery for prostate cancer has been carried out since 2006 in our hospital. Lian et al. addressed the preliminary results of 102 patients underwent primary cryoablation for clinically localized PCa from January 2006 to December 2009 in Nanjing Drum Tower Hospital. The early results of their study suggest that cryoablation offers a safe and effective alternative for the primary treatment of localized prostate cancer [24]. Recently, Zhou et al. analysed the results of a study of 23 patients with metastatic $\mathrm{BC}$ under percutaneous cryosurgery. No severe complications occurred in the study. The PFS of these patients was $14 \pm 8$ months, and indicated that percutaneous cryosurgery may be a safe and efficacious therapeutic option in the treatment of metastatic BC [5].

In the present study, we attempted to manage the aborted RC due to unresectable disease secondary to fixation to the pelvis and/or rectum (pT4b stage) and cryosurgery for these unresectable bladder cancer throuth transperineal approach. In this retrospective study, the longest 43 months of follow-up data from 7 patients obtained from our hospital's database were analyzed to determine the safety and efficacy of this procedure in bladder cancer (Fig. 1). In the study, all cryosurgical procedures for bladder cancer were performed successfully, with no treatment-related deaths. No severe preoperative, intraoperative or postoperative complications were happened. The therapeutic effect of transperineal cryoablation was evaluated by means of PFS. The PFS of the 7 patients who underwent comprehensive cryosurgery for unresectable bladder cancer was $22.00 \pm 14.61$ months, which was better than that reported for cisplatin monotherapy and M-VAC combination chemotherapy [26]. The 1-, 2- and 3 -year OS was $85.7 \%, 57.1 \%$ and $42.9 \%$ in the study, respectively. This study indicated that transperineal cryoablation may be an attractive alternative treatment for unresectable pT4b stage bladder cancer. This technique also could applicable to patients who could not tolerate cystectomy due to the minimal invasion. 
According to our preliminary experience of transperineal cryosurgery for unresectable MIBC of 7 male patients, we believe that the following is the key to ensure cryotherapy successful. Firstly, the use of TRUS to monitor the appearance of the ice ball as well as to guide cryoprobe placement to avoid any injury to other tissues, especially rectum. Secondly, the placement of temperature monitoring probes around tumor and rectum to enhance the temperature information provided by TRUS. Moreover, the success of this procedure benefits from the previous experience of transperineal cryosurgery for prostate cancer in our hospital. Furthermore, patient selection is also very important.

In this study, we describe a cryosurgery alone, cryochemoradiation or cryo-chemotherapy combination as an alternative treatment in unresectable pT4b stage bladder cancer. We believe that reduction local tumor burden through cryosurgery and followed with chemoradiation or chemotherapy will benefit more than chemoradiation or chemotherapy alone for locally advanced BC. Moreover, we believe that patients with the pT4b stage unresectable disease will benefited more from this procedure than pN2-3 patients. However, the retrospective design raises the issue of potential selection bias which are likely to have influenced the results of the present study. Moreover, it is limited by its small series and single-institution study design. Future prospective, large-scale and long-term studies are needed in multiply centers.

\section{Conclusions}

Transperineal cryoablation combination with chemoradiotherapy may be an option in the treatment of unresectable invasive bladder cancer due to unresectable disease secondary to fixation to the pelvis and/or rectum (pT4b) and these patients who could not tolerate cystectomy. The side effects were relatively mild and a PFS of $22.00 \pm 14.61$ months can be achieved. A larger number of cases is required, however, and long-term survival following this therapy and its role in combination with other therapies awaits further research.

\section{Abbreviations}

BC: bladder cancer; CT: computed tomography; MIBC: muscle invasive bladder cancer; OS: overall survival; PFS: Progression free survival; PLND: pelvic lymph node dissection; RC: radical cystectomy; TRUS: transrectal ultrasound; TURBT: transurethral resection of bladder tumor; UD: urinary diversion

\section{Acknowledgements}

The authors would like to thank all our participants for their gracious participation in this study.

\section{Funding}

No funding was obtained for this study.

\section{Availability of data and materials}

The datasets supporting the conclusions of this article are available in the Nanjing drum tower hospital Medical Records Room data base (Nanjing, Jiangsu, China) repository.

\section{Authors' contributions}

QZ conception and design, acquisition of data, analysis and interpretation of data; drafting of manuscript. SWZ conception and design, acquisition of data, analysis and interpretation of data; drafting of manuscript. SZ conception and design, acquisition of data, or analysis and interpretation of data; drafting of manuscript. WW acquisition of data, analysis and interpretation of data. XZ acquisition of data, analysis and interpretation of data. YD analysis and interpretation of data. $\mathrm{HL}$ analysis and interpretation of data. $\mathrm{HG}$ conception and design, analysis and interpretation of data; drafting of manuscript, supervision. All authors have read and approved the final version of this manuscript.

\section{Authors' Information}

Department of Urology, Drum Tower Hospital, Medical School of Nanjing University, Institute of Urology, Nanjing University, 321 Zhongshan Road, Nanjing 210,008, Jiangsu, PR China.

\section{Ethics approval and consent to participate}

Informed consent was obtained for all participants and studies were approved by the Institutional Review Board at Nanjing drum tower hospital. The approval number was 201,104,453.

\section{Consent for publication}

Not applicable.

\section{Competing interests}

The authors declare that they have no competing interests.

\section{Publisher's Note}

Springer Nature remains neutral with regard to jurisdictional claims in published maps and institutional affiliations.

Received: 24 December 2016 Accepted: 31 August 2017

Published online: 09 September 2017

\section{References}

1. Siegel R, Ma J, Zou Z, Jemal A. Cancer statistics, 2014. CA Cancer J Clin. 2014:64(2014):9-29.

2. Kaufman DS, Shipley WU, Feldman AS. Bladder cancer. Lancet. 2009; 374(2009):239-49.

3. MCDONALD JH, TAYLOR CB, HECKEL NJ. Rapid freezing of the bladder: an experimental and clinical study. J Urol. 1950;64(1950):326-37.

4. Logan C, Brown M, Hayne D. Intravesical therapies for bladder cancer indications and limitations. BJU Int. 2012;110(Suppl 4):12-21.

5. $\quad$ Liang Z, Fei $Y$, Lizhi N, Jianying Z, Zhikai Z, Jibing C, Jialiang L, Kecheng $X$. Percutaneous cryotherapy for metastatic bladder cancer: experience with 23 patients. Cryobiology. 2014;68(2014):79-83.

6. Glenn JF, Alyea EP. Ureterocutaneous anastomosis. I. Experimental use of a surgical splint to prevent stricture. J Urol. 1960;83(1960):602-5.

7. Goldberg SN, Grassi CJ, Cardella JF, Charboneau JW, Dodd GD 3rd, Dupuy DE, Gervais DA, Gillams AR, Kane RA, Lee FT Jr, Livraghi T, McGahan J, Phillips DA, Rhim H, Silverman SG, Solbiati L, Vogl TJ, Wood BJ, Vedantham S, Sacks D. Image-guided tumor ablation: standardization of terminology and reporting criteria. J Vasc Interv Radiol. 2009;20(2009):S377-90.

8. Bellmunt J, Albiol S. Chemotherapy for metastatic or unresectable bladder cancer. Semin Oncol. 2007;34(2007):135-44.

9. Stein JP, Lieskovsky G, Cote R, Groshen S, Feng AC, Boyd S, Skinner E, Bochner B, Thangathurai D, Mikhail M, Raghavan D, Skinner DG. Radical cystectomy in the treatment of invasive bladder cancer: long-term results in 1,054 patients. J Clin Oncol. 2001;19(2001):666-75.

10. Herr HW, Donat SM. Outcome of patients with grossly node positive bladder cancer after pelvic lymph node dissection and radical cystectomy. J Urol. 2001;165(2001):62-4. discussion 64

11. Yafi FA, Duclos M, Correa JA, Tanguay S, Aprikian AG, Cury F, Souhami L, Rajan R, Kassouf W. Contemporary outcome and management of patients 
who had an aborted cystectomy due to unresectable bladder cancer. Urol Oncol. 2011;29(2011):309-13.

12. Dunst J, Rodel C, Zietman A, Schrott KM, Sauer R, Shipley WU. Bladder preservation in muscle-invasive bladder cancer by conservative surgery and radiochemotherapy. Semin Surg Oncol. 2001;20(2001):24-32.

13. Custodio S, Joaquim A, Peixoto V, Macedo JE, Faria AL, Macias E, Rego S, Araujo A. Metastatic renal cell carcinoma: the importance of immunohistochemistry in differential diagnosis. Case Rep Oncol. 2012; 5(2012):30-4.

14. Chen B, Zeng ZC, Wang GM, Zhang L, Lin ZM, Sun LA, Zhu TY, Wu LL, Zhang JY, Ji Y. Radiotherapy may improve overall survival of patients with $\mathrm{T} 3 / \mathrm{T} 4$ transitional cell carcinoma of the renal pelvis or ureter and delay bladder tumour relapse. BMC Cancer. 2011;11(2011):297.

15. von der Maase H, Hansen SW, Roberts JT, Dogliotti L, Oliver T, Moore MJ, Bodrogi I, Albers P, Knuth A, Lippert CM, Kerbrat P, Sanchez RP, Wersall P, Cleall SP, Roychowdhury DF, Tomlin I, Visseren-Grul CM, Conte PF. Gemcitabine and cisplatin versus methotrexate, vinblastine, doxorubicin, and cisplatin in advanced or metastatic bladder cancer: results of a large, randomized, multinational, multicenter, phase III study. J Clin Oncol. 2000; 18(2000):3068-77.

16. Guzzo TJ, Rogers CG, Deng CY, Bivalacqua TJ, Palapattu GS, Bastian PJ, Eisenberger MA, Schoenberg MP, Gonzalgo ML. Outcomes of patients after aborted radical cystectomy for intraoperative findings of metastatic disease. BJU Int. 2008;102(2008):1539-43.

17. Nagele U, Anastasiadis AG, Merseburger AS, Corvin S, Hennenlotter J, Adam M, Sievert KD, Stenzl A, Kuczyk MA. The rationale for radical cystectomy as primary therapy for T4 bladder cancer. World J Urol. 2007;25(2007):401-5.

18. Rodriguez SA, Arias FF, Bueno BC, Rodriguez-Patron RR, Sanz ME, Palacios VH, Burgos RFJ. Cryotherapy for primary treatment of prostate cancer: intermediate term results of a prospective study from a single institution. Prostate Cancer. 2014;2014(2014):571576.

19. Autran-Gomez AM, Scarpa RM, Chin J. High-intensity focused ultrasound and cryotherapy as salvage treatment in local radio-recurrent prostate cancer. Urol Int. 2012;89(2012):373-9.

20. Marcus DM, Canter DJ, Jani AB, Dobbs RW, Schuster DM, Carthon BC, Rossi PJ. Salvage therapy for locally recurrent prostate cancer after radiation. Can J Urol. 2012;19(2012):6534-41.

21. Sverrisson EF, Nguyen H, Kim T, Pow-Sang JM. Primary cryosurgery for clinically localized prostate cancer-do perioperative tumor characteristics correlate with post-treatment biopsy results. Urology. 2014;83(2014):376-8.

22. Schiffman M, Moshfegh A, Talenfeld A, Del PJJ. Laparoscopic Renal Cryoablation. Semin Intervent Radiol. 2014;31(2014):64-9.

23. Sverrisson E, Jones JS, Pow-Sang JM. Cryosurgery for prostate cancer: a comprehensive review. Arch Esp Urol. 2013:66(2013):546-56.

24. Lian H, Guo H, Gan W, Li X, Yan X, Wang W, Yang R, Qu F, Ji C. Cryosurgery as primary treatment for localized prostate cancer. Int Urol Nephrol. 2011; 43(2011):1089-94.

25. Hartman JB, Bhojwani N, Corn DJ, Cooney MM, Haaga J, Ponsky L, Abouassaly R, Paspulati A, Prologo JD. Incidence of hypercoagulable events after image-guided percutaneous cryoablation of renal tumors: a singlecenter experience. J Vasc Interv Radiol. 2014;25(2014):776-9.

26. Sr LPJ, Einhorn LH, Elson PJ, Crawford ED, Kuebler P, Tannock I, Raghavan D, Stuart-Harris R, Sarosdy MF, Lowe BA, et al. A randomized comparison of cisplatin alone or in combination with methotrexate, vinblastine, and doxorubicin in patients with metastatic urothelial carcinoma: a cooperative group study. J Clin Oncol. 1992;10(1992):1066-73.

\section{Submit your next manuscript to BioMed Central and we will help you at every step:}

- We accept pre-submission inquiries

- Our selector tool helps you to find the most relevant journal

- We provide round the clock customer support

- Convenient online submission

- Thorough peer review

- Inclusion in PubMed and all major indexing services

- Maximum visibility for your research

Submit your manuscript at www.biomedcentral.com/submit
) Biomed Central 